\title{
CONSTITUCIONALISMO CONTEMPORÂNEO: OS DESAFIOS NA ERA DA
}

\section{GLOBALIZAÇÃO.}

\begin{abstract}
Alessandra Monteiro Machado ${ }^{1}$
Resumo: A definição de globalização e o constitucionalismo contemporâneo são importantes para explicar a importância dos princípios fundamentais na construção de um sistema de interesses coletivos ou globais.
\end{abstract}

Palavras-chave globalização - constitucionalismo - princípios fundamentais

\begin{abstract}
The definition of globalization and contemporary constitutionalism are important to explain the importance of the fundamental principles in the construction of a collective or global interests system.
\end{abstract}

Key words: globalization - constitutionalism - fundamental principles

1. Globalização: dificuldades em definição

Acredita-se, que a primeira dificuldade posta ao tema relativo a "globalização", trata- se de sua própria definição. Numa tentativa de se chegar a um conceito que venha amparar as fragilidades que surgem, tanto no âmbito do direito constitucional, como no próprio âmbito do direito internacional e respectivamente das relações internacionais, nos deparamos com a fatal

\footnotetext{
${ }^{1}$ Doutoranda pela Faculdade de Direito da Universidade de Lisboa, com ênfase em Direito Constitucional. Mestre em Direito - 2012 - área de Ciências Jurídico Políticas, pela Faculdade de Direito da Universidade de Lisboa. Pós graduada em Direito Constitucional, pela Faculdade de Direito da Universidade de Lisboa - 2010. Graduada pela Universidade do Vale dos Sinos - Unisinos. Pesquisadora do Grupo de estudos Jorge Miranda - eixo de Direito Constitucional, desde 2013. Presidente do Núcleo de Estudantes Luso-brasileiros - Faculdade de Direito da Universidade de Lisboa, Gestão 2013 - 2016. Professora Universitária.
} 
necessidade de compreendermos que tal fenômeno "globalização", ou melhor dizendo, da "plural e heterogênea fenomenologia da globalização" ${ }^{2}$, teve início com a mobilidade da própria sociedade. Diante dessa tentativa, eis que tal fenômeno deve e merece ser interpretado como um processo resultado de uma série de diferentes processos e não um processo casual, único em si.

Essa relação as novas complexidades internacionais que surgem, nos demonstram alguns desafios, entre eles: a nova natureza dos conflitos pode estar relacionada a estreita relação da economia política da globalização com os mais novos conflitos que surgem no século XXI, das coalizões lideradas pelas atuais potências emergentes — neste caso específico o Brasil e países do Sul, a crise do multilateralismo que nos demonstra obviamente que estamos diante de novos egoísmos nacionais e principalmente da incalculável dificuldade em construirmos uma sociedade internacional contemporânea com lastros baseados no consenso.

Diante dessa realidade, eis que surge uma indagação. Num mundo globalizado quem cuida do bem comum mundial? Vivemos numa transição e ainda não existe resquícios profundos que indiquem um enquadramento político para a globalização, logo nos faz crer que os mercados acabarão prevalecendo, com eles citamos as empresas multilaterais, pois em muitos casos possuem uma capacidade política muito considerável e com voz ativa politicamente dentro de alguns Estados. Com tais perspectivas nos direcionamos cada vez mais para os mercados globais que acabam ditando as vontades políticas a serem conduzidas pelas nações.

Dessa forma, nos falece o controle da democracia que é usurpada pelos novos atores do cenário internacional. Aliás, é nitidamente a economia a prevalecer sobre a política, ou será conduzindo a nova política com moldes orientados por uma política especificamente econômica. Assim, percebemos um viés diferenciado da globalização. No entanto, são as desigualdades que persistem numa era em que os progressos das ciências e das tecnologias permitem um esquecimento de questões globais relevantes que envolvem imensos riscos e um agravamento

${ }^{2}$ SÁNCHES, Luis Pietro. Constitucionalismo y globalización. Dimensiones Jurídicas de la globalización. Madrid, 2007, p. 45 e segs. 
assimétrico.

Diante dessas abordagens nos questionamos no seguinte compasso: a globalização traz consigo associada a competitividade? Quem garante que com ela esteja atrelada questões que envolvam aspectos de um aprimoramento da solidariedade, onde o mundo passa a ser mais global em matérias de assuntos referentes aos Direitos humanos? Definitivamente, ainda estamos distantes dessa solidariedade global, em prol de uma humanidade mais homogêna.

Diante de todas as mazelas da globalização, ainda precisamos ter em mente que o simples fato de associarmos todos os problemas em pauta nas atuais sociedades modernas como de única responsabilidade do fenômeno da globalização, eis que assim, estaríamos entrando num plano totalmente descabido, em virtude de vários acontecimentos serem explicados por outras áreas que podem estar interligadas entre si e não somente pelo contexto jurídico. Aliás, o mundo global e as constituições contemporâneas, cada vez mais nos remetem a ideia de interligação das mais diversas áreas, para novos contextos jurídicos. Seriam os novos direitos, em busca de explicações e soluções jurídicas, em virtude dos atuais comportamentos sociais. Com a velocidade do crescimento das sociedades, é inevitável que com esse processo nao surjam novos conflitos, novos direitos e muitas vezes direitos que se tornam transfronteiriços ou indo mais além, verdadeiros conflitos internacionais entre Estados de extrema importância política no cenário global.

A globalização, num outro prisma, também pode ser analisada sobre o efeito de um processo crescente de abertura, alguns autores conduzem o tema para internacionalização ${ }^{3}$, podendo

\footnotetext{
${ }^{3}$ Sobre a distinção entre internacionalização, mundialização e globalização, bem ressalta Bárbara Maria da silva CRUZ ao dizer: "a mundialização teve o seu culminar com os grandes descobrimentos do século XV, através de acção de descobrir e ocupar o mundo, colocando-lhe fronteiras e em que os grandes protagonistas eram os actores nacionais. Quanto a internacionalização, enquanto processo posterior, traduziu-se, em particular, pela criação de instâncias inter e supranacionais de âmbito predominantemente político e jurídico, em que, não obstante se continuar a reconhecer a existência de fronteiras, os Estados começam a aceitar a sua abertura em prol de determinados interesses comuns. No que tange a globalização, como processo mais complexo e também mais recente, é por isso mesmo mais difícil de definir. Cfr. CRUZ, Ana Maria da Silva. Constitucionalismo. Desafios emergentes na era da globalização. Teoria da Argumentação e Neo-Constitucionalismo. Um conjunto de perspectivas. HESPANHA, António Manuel; Tereza Pizarro Beleza (Coord.). Coimbra, 2011, p. 11 e segs.
} 
ser inclusive internacionalização dos interesses econômicos ${ }^{4}$, onde mencionam que tal conduta fortaleceu as economias capitalistas centrais e, sendo assim, torna dependente as economias menos desenvolvidas e periféricas, mas há quem fale em supressão das economias nacionais ao fluxo das mercadorias e capitais alienígenas, seja pela permissividade das políticas adotadas pelos Estados, como a uniformidade de tratamento entre o capital nacional e o capital estrangeiro, seja pela queda das barreiras alfandegárias e entraves variados (como o excesso de intervenção estatal na seara econômica), com vistas de formação de um mercado global unificado. Disso resulta o seu caráter prevalentemente econômico, podendo ser visualizada sob variadas perspectivas: a globalização produtiva, a globalização financeira, a globalização dos mercados, a globalização da concorrência"5.

Mesmo não existindo um conceito fechado que possa definir a globalização, o que é unânime é a sua estreita aproximação entre todos no mundo que torna-se, cada vez mais globalizado, tanto é verdade que antigamente cada Estado possuía os seus problemas fundamentais. No mundo globalizado, esses problemas fundamentais passaram a ser de todos os povos, muitos desses problemas fundamentais ultrapassam as barreiras estatais e se tornam "problemas fundamentais globais". Porém, nas mais variadas formas de interpretá-los, eis que surgem mais problemas até atingirem um consenso, coisa que não tem sido nada fácil, diante de processos complexos e recentes de se compreender nas mais diversas esferas. O que justifica a necessidade nessas tendências de inter-relação que compõem o cenário dessa sociedade contemporânea, que

\footnotetext{
4 Sobre o tema internacionalização dos interesses econômicos e principalmente sobre seus efeitos sobre as transformações do Direito Internacional vale os seguintes contributos de Wolfgang FRIEDMANN ao dizer: "A internacionalização cada vez maior da indústria, comércio e dos negócios nos estágios adiantados da revolução industrial e a consequente internacionalização das atividades da empresa moderna estão desafiando o monopólio legal e político do estado. Eles criam, no direito e nas relações internacionais contemporâneas, novos problemas de tensão entre organização política ainda predominante no mundo em estados nacionais soberanos, e a internacionalização dos interesses e atividades econômicas. O estado nacional ainda reivindica lealdade legal, política e emocional, conforme é demonstrado pela atitude da grande maioria dos cidadãos na ocorrência da guerra. (...) Mas a internacionalização de interesses econômicos criou importantes reivindicações antagônicas que às vezes entram em conflito com as lealdades ao estado, à medida que a organização dos interesses econômicos se difunde além das fronteiras nacionais." Ver em FRIEDMANN, Wolfgang Gaston. Mudança da estrutura do Direito Internacional. Tradução de: A.S. Araujo, Rio de Janeiro, 1971, p. 25 e segs.

${ }^{5}$ Cfr., WANDERLEY JUNIOR, Bruno; Dalvo Leal da Rocha. Processo de integração e globalização: um contraponto entre o discurso neoliberal e a construão de um espaço comunitário. Direito Internacional Contemporâneo. Leonardo Nemer Cladeira Brant, et. al. Curitiba, 2011, p. 729 e segs.
} 
fazem parte de um conjunto variado de coincidências políticas, tecnológicas, econômicas, sociais, culturais que atuam na prática da realidade das sociedades contemporâneas e acabam por impregnar todo o cenário internacional.

Acredita-se, que a mais próxima definição de globalização é tangida por Boaventura de Souza SANTOS ao referir: "Definimos globalização, como conjunto de relações sociais que se traduzem na intensificação das interações transnacionais, sejam elas práticas interestatais, práticas capitalistas globais ou práticas sociais e culturais transnacionais" ${ }^{6}$. Importa salientar que todo esse conjunto nos direciona para a formação de uma nova realidade global formada por uma sociedade internacional.

Essa nova sociedade internacional nos permite estar em tempo real e vivenciar a construção dessa nova ordem em transição, onde mais do que nunca permanece interligada por canais de conexão transnacionais.

\section{O Constitucionalismo Contemporâneo}

Em tempos de globalização, desde que o positivismo jurídico tradicional passa a ser questionado sobre a função do Estado e do Direito, torna-se salutar que democracias advindas de regimes totalmente autoritários busquem a maior efetividade dos processos democráticos e dos direitos fundamentais. Com a transição do Estado de Direito para o Estado constitucional de Direito, a Constituição surge como instrumento que passa a dar forma ao regime político, orientase, por determinados princípios estruturantes. Da mesma forma, também promove a dignidade da pessoa humana e os direitos fundamentais como verdadeiros contributos do Estado Democrático de

${ }^{6}$ SANTOS, Boaventura de Souza. A globalização e as ciências sociais. O processo da Globalização. São Paulo, 2002 , p. 85. 
Direito.

Em relação aos poderes de governo, a constituição torna-se, um veículo limitador dos poderes dos governantes e, no mesmo sentido, surge como verdadeiro incentivador dos direitos das pessoas. ${ }^{7}$ É, pois, no âmbito dessas ideias que a sociedade começa a ter mais liberdade de expressão e uma busca mais idealizadora nos direitos fundamentais.

Portanto, é notório que o contemporâneo constitucionalismo, encontra-se, diante do conflito de propostas diversas, embora não antagônicas que procuram definir o papel que realmente deve exercer a Constituição. De fato, busca-se, uma forma que possa oferecer aos mais céticos algumas respostas adequadas sobre o sentido e fundamentação da Constituição, do ponto de vista da imutabilidade normativa "cláusulas pétreas", em detrimento de futuras gerações e sua força majoritária.

Assim, o que percebe-se é a transformação do mundo contemporâneo num bloco intercambiável, solidário com outras dimensões, onde vem exigindo do Estado uma atuação célere, em relação as crescentes demandas. No que concerne à administração pública, vislumbra-se como uma verdadeira gestora dos interesses sociais. Assim, com as crescentes demandas, com essa celeridade resultou na releitura da legalidade administrativa, muitas vezes gerando um conflito entre o poder dos juízes que aparentemente nos caracteriza como uma sobreposição ao próprio direito.

Diante desse nova percepção e considerando o paradigma da força normativa da Constituição, os princípios constitucionais nos demonstram cada vez mais o quanto são normas abertas, sujeitando-se ao intérprete e aplicador do direito funções típicas do Poder Judiciário. Diante desse cenário, vislumbramos o ativismo judicial, fenômeno que recebeu impulso no

\footnotetext{
${ }^{7}$ Em Ana Maria Guerra Martins, podemos encontrar a ideia bem desenvolvida sobre o constitucionalismo nacional e sua transformação recente em Estado moderno. Desta forma, percebemos a constituição como um conjunto de normas que confere uma unidade social e política à organização de uma determinada sociedade. Manual de Direito da União Europeia. Almedina, 2014, p. 36.
} 
moderno constitucionalismo, porém, precisamos ter em mente que tudo isso vem resultando na livre construção do direito pelo guardião da Constituição. Assim, submetendo os atos do poder público à definição dos critérios judiciais em função de uma flexível e subjetiva interpretação e, indo mais além, caberiam as palavras do nobre constitucionalista Lênio STRECK, ao dizer: “o Estado Democrático de Direito proporcionou um nova configuração nas esferas de tensão dos Poderes do Estado, decorrente do novo papel assumido pelo Estado e pelo constitucionalismo, circunstância que reforça, sobremodo, o caráter hermenêutico do direito." ${ }^{8}$ O que o autor refere-se diz respeito ao raciocínio, mesmo que independente da hermenêutica filosófica, porém, ainda, necessitamos de respostas concretas em matéria de Direito.

Um grande desafio do constitucionalismo contemporâneo é justamente a necessidade em manter-se a garantia da legalidade e a democracia constitucional. De fato, o direito contemporâneo prescinde de uma leitura à luz dos direitos fundamentais e da soberania popular para fomentar a realidade internacional. É notório, que esse novo processo constitucional envolve valores, onde passa a ser parte efetiva via participação democrática, onde passa a substituir a coercibilidade tradicional do sistema jurídico pela força dos princípios jurídicos ${ }^{9}$. Aliás, é justamente no momento em que as Constituições deixam de ser um simples esboço de princípios orientadores e, assim, passam a se converter em verdadeiros sistemas de normas constitucionais com força jurídica vinculante, onde estabelecem os mais rigorosos mecanismos de controle do poder. Eis, que assim, apresentam com total contundência os efeitos da globalização econômica, um dos grandes impulsionadores de poder e com um relevante papel decisório em Estados emergentes, em fase de expansão. Com tais vetores, nasce a impotência generalizada do Estado face a tal fenômeno ${ }^{10}$.

\footnotetext{
${ }^{8}$ Cfr. STRECK, Lênio Luiz, op. cit., p. 378. O livro nos direciona para a instigação de uma nova construção do direito e, num dos tópicos, o autor aborda de forma crítica a hermenêutica e a democracia: discricionariedades interpretativas, suas decorrências e consequências. Expõe como o problema é paradigmático.

${ }^{9}$ Cfr. QUEIROZ, Cristina. Constituição, Constitucionalismo e Democracia. MIRANDA, Jorge (Org.). Perspectivas Constitucionais nos 20 anos da Constituição de 1976. Coimbra, 1996, p. 457 e segs.

${ }^{10}$ Cfr. GARCIA, Pedro de Vega. Mundialización y Derecho Constitucional: la crisis del Principio Democrático en el Constitucionalismo actual. Revista de Estudios Políticos. Madrid, n. ${ }^{\circ}$ 100, 1998, p. 29.
} 
O que devemos preservar são os valores, os princípios jurídicos e não a mera efetivação da constituição positivada como norma e força jurídica, pois a força jurídica, muitas vezes está alicerçada em força política, ou até mesmo, em força econômica, mas o que está por vir em tempos atuais? Um Constitucionalismo que transcenda, as barreiras nacionais e demonstra a força normativa da constituição com novos direitos fundamentais, com direitos sociais, em grande evidência de preservação, não só na esfera estatal, mas sim na esfera internacional. Ora, bem sabemos, que é necessário e indispensável uma real efetivação diante de um novo direito constitucional, que sem dúvida alguma, resguarde a preservação dos valores dos direitos fundamentais.

A partir do paradigma do pluralismo jurídico emergente da globalização, deve-se, urgentemente, adequar-se a nova realidade constitucional imposta pela nova realidade internacional que certamente, impões constantemente "pontos de partida da compreensão/ explicação do "mundo" subjacente ao chamado constitucionalismo global"11. Indo mais além, percebe-se, claramente, que os pontos de partidas seriam: democracia e os próprios caminhos para a democracia, por tais razões, considera-se, como um verdadeiro veículo de inserção e imprescindível intensificador da paz entre os povos.

Sobretudo, as relações internacionais exercem um papel preponderante para o constitucionalismo contemporâneo, em virtude de amenizar os desafios advindos com o processo da globalização. Assim, passam a desempenhar um papel regulador no que pertine ao direito internacional e nesse aspecto, salientamos a imposição advinda com o núcleo duro de jus cogens.

Alega-se, através da doutrina e neste caso, cita-se Gomes CANOTILHO, quando refere

\footnotetext{
${ }^{11}$ Indo mais além, José Joaquim Gomes CANOTILHO, elenca os traços desse novo paradigma emergente da seguinte forma: 1) alicerçamento do sistema jurídico-político internacional não apenas no clássico paradigma das relações horizontais entre estados (paradigma hobbesiano/westfaliano, na tradição ocidental) mas no novo paradigma centrado nas relações entre Estado/povo (as populações dos próprios estados); 2) emergência de um jus cogens internacional materialmente informado por valores, princípios e regras universais progressivamente plasmado em declarações e documentos internacionais; 3)tendencial elevação da dignidade da pessoa humana a pressuposto ineliminável de todos os constitucionalistas. Este paradigma emergente que alguns pretendem designar como constitucionalismo global não está ainda em condições de neutralizar o constitucionalismo nacional. Cfr Cfr. CANOTILHO, José Joaquim Gomes, op. cit., p. 1369 e segs.
} 
sobre o Jus cogens alengando ser um verdadeiro "vertebrador quer da polítcia e relações internacionais $^{e 88}$. Com isso, percebe-se, a presente evolução da sociedade, em desenvolver-se no cenário internacional, sendo assim, o "Jus cogens” merece breves considerações para podermos compreender melhor e o atual rumo das fontes, das regras e das normas no plano internacional.

Nota-se, com grande relevância uma nova tendência de produção de normas no Direito Internacional, assim, observa-se, que são totalmente opostas onde no que cabe ao jus cogens, percebe-se que são consideravelmente rígidas e no que se refere ao soft low, são meramente flexíveis, mas o que nos permite e nos direciona para um olhar mais curioso é a finalística, tanto do jus cogens como do soft low, visto que ambas atingem os Estados. Cabe porém, verificar qual a intensidade e como essas normas jurídicas vinculam e obrigam os Estados assim, vislumbramos mais um dos grandes desafios do constitucionalismo contemporâneo, pois cabe as constituições se moldarem e recepcionarem as normas internacionais com uma intensidade mais aberta, sem ferir os princípios estruturantes de cada Estado.

O Jus cogens ${ }^{12}$, está muito ligado ao direito internacional geral, onde são reconhecidos pela sociedade internacional, com relação direta com as normas de Direito Internacional, indo mais além, alguns doutrinadores chegam a revelar que o existem alguns princípios fundamentais de direitos internacional e os mesmos são formados por um corpo de jus cogens .

Com essa nova realidade internacional, nota-se, uma necessidade por parte da doutrina tentar classificar alguns princípios como fundamentais, talvez pelo fato, de sua importância dentro do contexto internacional e também nacional, visto que os princípios, possuem uma força normativa muito grande, sabemos perfeitamente que não existe hierarquia entre as fontes, porém, é considerável a carga estruturante que revelam os princípios, assim acabam, falsamente, por desempenhar uma certa hierarquia e nesse sentido concebe-se o jus cogens (norma geral de Direito

\footnotetext{
${ }^{12}$ Sobre essa temática, v., FIORATI, Jete Jane. Jus Cogens: as normas imperativas de Direitolinternacional Público como modalidade extinta dos tratados internacionais. Franca, 2002, p. 155; Também RODAS, João Grandino. Jus Cogens em Direito Internacional. Revista da Faculdade de Direito de São Paulo. São Paulo, vol. 69, fasc. II, 1974, p. 125 e segs.
} 
Internacional) onde ficaria claramente demonstrado que os princípios não poderiam ser alterados por tratados ou costumes, tanto que podemos vislumbrar pelo art. $53^{\circ}$, da Convenção de Viena sobre os tratados.

Outra tendência visível da globalização, refere-se, a inversão dos problemas internacionais e os problemas internos de cada país. É cada vez mais perceptível que os internacionais já não são apenas parte dos nacionais, nos demonstrando assim, que passaram a estar acima deles. Colocaram-nos, sob sua dependência. Os problemas nacionais, evidentemente continuam sendo de extrema relevância para seus respectivos povos, de tal forma, percebemos a instabilidade, em resposta ao próprio desenvolvimento mundial que a cada dia nos é mais instável nos acontecimentos, uma prova disso é o 11 de Setembro e a invasão do Iraque. Tudo indica que os problemas nacionais deixaram de comportar soluções efetivas e duradouras na falta de um contexto mundial mais favorável. De fato, é preciso criar um ambiente internacional que contribua para a solução dos problemas nacionais, onde não dificulte cada vez mais sua solução.

Nessa perspectiva, a criação de uma jurisdição universal só viria a fomentar questões que exigem de ambos os planos, um tratamento rápido, único e eficaz, diante de um consenso prévio dos Estados que convencionaram tal intenção. Nesse quadro de desafios, eis que surge, uma indagação em torno da atual incapacidade de respostas, tanto por parte dos Estados e até mesmo do direito às relações internacionais, no que tange a um pensamento único em relação a uma constituição global ou mundial. Seria possível diante desse cenário tão conturbado? A fragmentação das sociedades cresce velozmente, pelos mais variados fatores culturais, ao ponto de desacreditarmos no consenso, de fato, tem sido algo cada vez mais distante em matéria de preservação constitucional dos direitos fundamentais, em relação as liberdades fundamentais. Sobre esse aspecto, a Europa nos parece mais engajada nessa tentativa, vejamos o comportamento do TUE - Tratado da Constituição Europeia. Na atualidade que vislumbramos, não deixa de ser uma verdadeira constituição em moldes transnacional, pois torna-se, necessário salientarmos que o presente documento não mais considera-se pela sua desenvoltura como um simples tratado, em 
virtude de adquirir novas proporções, tanto que é um verdadeiro organizar político de toda a União

Europeia. Ora, um exemplo bem claro surge desde a tentativa realizada pelo Tratado da União

Europeia que hoje concretiza-se com o Tratado de Lisboa. ${ }^{13}$ Quem sabe num futuro próximo

vivenciamos uma constituição global.

Sendo assim, não restam dúvidas que estamos diante de "tendências", onde a prática

nos direcionam numa busca por novos caminhos, mesmo diante de tantas críticas. As novas

tendências atingem as mais diversas áreas e os movimentos constitucionalistas se desenvolvem de

forma natural. O curioso é que no âmbito do projeto cosmopolita de KANT, o mesmo desenvolve a

ideia da ampliação do conceito de "constituição" do âmbito nacional a um nível mundial, através

de uma república mundial, antecipando assim, a defesa da constitucionalização das relações

internacionais tão em voga atualmente ${ }^{14}$. Eis, que cada vez mais nos utilizamos da história, em

busca de um desenvolvimento global mais adequado para os Estados e a comunidade internacional.

Outro ponto que merece ser analisado refere-se, a necessidade imposta aos Estados em

acompanhar as mudanças advindas com o novo cenário global, de fato salientamos que para uma

\footnotetext{
${ }_{13}$ Sobre essa temática é indispensável os contributos de Ana Maria Guerra MARTINS ao demonstrar, a seguinte perspectiva: "O Tratado da União Européia organiza o poder político dentro da União Européia, através da repartição de atribuições entre os Estados Membros e a União, bem como da repartição dos poderes entre os órgão da União, estabelecendo as bases que permitem desenvolver a proteção dos direitos fundamentais dos cidadãos. O Tratado encontra-se numa posição hierárquica superior tanto em relação às normas produzidas na união como em relação às normas de produção estadual, prevendo mesmo o controle judicial da constitucionalidade e da legalidade das mesmas. Além disso, o Tratado contém regras mais rígidas para a sua revisão do que para a elaboração do direito derivado. De referir ainda que o Tratado tem subjacente idéia de Direito que assenta nos valores da liberdade, da democracia, dos Estado de Direito, da proteção dos direitos fundamentais, da justiça social e do pluralismo cultural, isto é, possui uma base axiológica própria. É evidente que a aceitação do caráter constitucional do Tratado da União Européia pressupõe a libertação dos postulados tradicionais da ciência política, que vêm desde o século XVIII, pois só assim se pode admitir a autonomia da noção de constituição em relação ao Estado. A teoria constitucional da pós-modernidade tem de partir de um constitucionalismo global, no qual a constituição estadual deve ser encarada como uma das suas partes componentes a par de outras. A constituição da União Européia é uma constituição cujo poder constituinte não é produto de uma ruptura com a ordem constitucional vigente, mas antes evolui lentamente, manifestando-se, sobretudo, através de um poder de revisão, de adesão e de desenvolvimento. Esta constituição encontra-se ainda em formação, pelo que existem certos problemas que não estão satisfatoriamente resolvidos, como, por exemplo, o da sua legitimidade democrática. Trata-se de uma constituição em transformação, a qual sofre a influência de todos os intervenientes no processo de integração. A constituição da união não é auto-suficiente, necessitando das constituições dos Estados membros, que completa e é por elas completadas. Por fim, a constituição da União é uma constituição que não tem, à partida, fins determinados." Cfr. MARTINS, Ana Maria Guerra, op. cit., p. 165 e segs. Vale frisar, os irlandeses rejeitaram em referendo, em junho de 2008, o Tratado de Lisboa é considerado a versão mais suave já proposta para a Constituição Europeia. Aliás, o respectivo documento que entrou em vigor em 1 de Dezembro de 2009, passa a conferir à União Europeia instituições modernas e métodos de trabalho eficientes que lhe permitirão dar uma resposta efectiva aos desafios actuais da globalização.

${ }^{14}$ HABERMAS, Jurgen. Es possible uma constitución política para la sociedade mundial pluralista? Law and justice in a global society. Anales de la Cátedra Francisco Suárez. Granada. n. ${ }^{\circ}$ 39/2005, p. 107 e segs.
} 
boa política global, os Estados irreversivelmente necessitam crescer para além das típicas formas de cooperação intergovernamental. É preciso, uma interação com os novos atores do cenário internacional, aliás, tais atores, também surgem no seara nacional, são os efeitos do redirecionamento da globalização que afetam, tanto os Estados, onde pedem o reforço de medidas, de normas nacionais, como também o reforço internacional, pois o verdadeiro desafio emergente reside justamente nesse comportamento dos novos atores globais, em virtude de buscarem, sem controvérsias a eficácia das normas e isso independe do local de atuação. Basta, apenas a concretização final, a eficácia sendo materializada, em prol de um direito almejado e consubstanciado normativamente.

Diante desse cenário, quais seriam, as perspectivas em relação a globalização soberania? Em alguns casos, a soberania, falsamente, nos demonstrava estar num processo de diminuição, pelo menos na visão de alguns autores. Porém, diante da perspectiva almejada pelo próprio Estado, onde se impõem, cada vez mais, em tempos atuais, uma postura diante da conjuntura internacional, onde os direitos estão sendo cobrados além do Estado, e não só dentro do Estado. Nesse contexto global de soberania, o que estamos vislumbrando é um avanço dessa soberania, um alargamento incontestável, diante de uma efetiva transformação de estrutura e da natureza da comunidade política internacional e nacional.

\section{A importância dos princípios fundamentais na construção de um sistema de interesses coletivos ou globais}

Ao estudarmos o Direito, bem compreendemos sobre a importância dos princípios na formação de qualquer ordenamento, tanto que o direito internacional não é composto exclusivamente pelas suas normas avulsas, muito menos pela vasta criação de acordos e tratados, nesse aspecto, bem sinaliza Jorge Miranda: “compreende regras e princípios, e apenas os princípios 
— logicamente anteriores — permitem integrar as regras num todo sistemático, ultrapassar o seu caráter parcelar, fragmentário e, por vezes, conjuntural, e submetê-las a comuns critérios de interpretação e aplicação" ${ }^{15}$. De fato, possuem natureza de normas jurídicas vinculantes, nos revelam uma dimensão de peso, assim, nos é perceptível que os mesmos exercem capacidade de direcionar, nortear ou seja, realmente abrem caminhos para soluções jurídicas, mas caso colidam é necessário a sua ponderação.

Com a transformação do cenário internacional, verificamos dentro da seara dos princípios, uma mudança em relação a sua prevalência, ou seja, alguns princípios que eram tidos como princípios fundamentais de extrema relevância nas décadas passadas perdem seu lugar de prevalência em detrimento de outros princípios. Diga-se de passagem, alguns deles nem elencados na Carta das Nações Unidas o são, diante disso, nos deparamos com novos contornos do cenário internacional, onde princípios de prevalência global, coletiva estão indubitavelmente na pauta das grandes reuniões e anseios da humanidade. Um exemplo bem óbvio trata-se, do princípio de preservação do meio ambiente, considerado como um verdadeiro manifesto de princípio da atualidade, não temos dúvida alguma. Aliás, a Millenium Declaration ${ }^{16}$, nos esboça categoricamente os objetivos desenvolvidos como metas para o milênio.

Ao mencionarmos sobre princípios, muito se tem escrito sobre o lugar dos Estados como verdadeiro sustentáculo das relações internacionais e principalmente como um principal destinatário do direito internacional. Observamos que tal assertiva não mais vigora nesse processo de transição do direito internacional, tanto que visualizamos a crescente entrada de novos atores. Diante dessas perspectivas nos deparamos com a ruptura do modelo estatal e com isso cada vez mais vivenciamos a mudança de paradigmas.

\footnotetext{
${ }^{15}$ MIRANDA, Jorge, op. cit., p. 117.

${ }^{16}$ Disponível em: http://www.un.org/millennium/declaration/ares552e.htm. Acesso em: 23 de maio de 2012. A presente Declaração é um documento de extrema importância, pela inovação em trazer a baila temas da atualidade e que merecem um respaldo e proteção mais específicos. Nessa última Declaração, observamos que a mesma passa a dedicar longo conteúdo aos valores e princípios, onde percebemos que novos princípios fundamentais, ausentes da carta da ONU, são tão bem desenvolvidos na Declaração do Milênio como a preservação do meio ambiente e o da luta contra a pobreza.
} 
De fato estamos tornando mais irrelevante as barreiras impostas pela soberania, onde caminhamos constantemente pela defesa de direitos humanos, a crescente criação de tribunais penais internacionais e intervenções e também a crescente intervenção de processos humanitários. É uma prova cabal de que o modelo estatal está aos poucos cedendo seu terreno em prol de direitos globais a serem preservados e não somente a vontade estatal como prevalecente.

Na realidade vislumbra-se, um caráter mais compromissório dos princípios, onde a prática cada vez mais tem exigido uma necessidade em conciliar, onde a tendência está centrada na flexibilização na hora de aplicar uma norma, pois o modelo anterior ainda é muito presente. Diante de tais esboços, é imprescindível que se mencione que os princípios são a quintessência do direito internacional e nesta perspectiva é compreensível que são representativos de toda uma evolução histórica, política, econômica, jurídica e também social da comunidade. Nesse condão é de extrema valia o quanto os mesmos estão sendo aflorados numa ordem jurídica futura. Observa-se, que o artigo $2^{\circ}$ da Carta da ONU, esboça categoricamente quais os princípios merecem serem invocados na hora de justificar uma tomada de resolução. Porém, a cada novo chamamento de princípios percebe-se vertiginosamente a alteração que pode ocorrer no cenário internacional, o fato reside inclusive no vislumbre de novos princípios que não estão presentes na carta. Ora, estamos diante de uma alteração qualitativa que também procura acompanhar essa evolução.

Assim, passamos a análise de alguns princípios que pareciam adormecidos ou totalmente estáveis num cenário internacional que se quer considerava-se como princípio relevante ou em causa. No presente menciona-se tanto sobre a aceitação do direito de ingerência nos assuntos interno dos Estados, o grande expoente da proteção da soberania.

Porém, está totalmente envergado em benefício de assistência humanitária como no século XXI. No que refere a soberania e sua forma de manter o quase inquestionável "domínio reservado" em tempos globais, em tais moldes, eis que surge a ampliação desses domínios que não mais consideram-se tão reservados assim, trata-se da quebra da rigidez. 
Assim percebe-se objetivamente o caminhar claramente, em direção a uma possível tentativa em darmos espaço alargado ao consenso, pois nos retrata o quanto merece prevalecer na análise de todos os confrontos advindos de uma órbita de Estados nacionais, nos quais merecem apreciação num Tribunal Penal Internacional. É o que verificamos no clássico caso da proibição de extradição de nacionais, baseado na soberania territorial, porém é indubitável que se repense na hipótese de cooperação com uma ordem jurídica da comunidade mundial ${ }^{17}$, em virtude da implementação do Tribunal Penal Internacional, onde serão analisados assuntos que exigirão uma cooperação, um consenso por parte dos mais variados Estados e diante das mais diferentes culturas.

Um dos princípios que está em constante ascensão refere-se ao princípio dos Direitos Humanos, a passos largos e firmes demonstra nesse novo século, através de seus fundamentos o quanto é um verdadeiro sedimentador em busca de solidariedade, democracia e preservação paz. Além de acreditar-se que consubstancia-se como um real reforço aos demais princípios como: princípio da solidariedade, da dignidade da pessoa humana, da igualdade, da proibição do excesso e o vetor do Estado Democrático de Direito. Dessa forma, consegue-se compreender a sua dimensão, tanto na aplicabilidade no plano interno e internacional, onde exercem uma funcionalidade fundamental, em matéria de preservação e solidificação da humanidade em tempos tão devastadores impostos pela globalização.

Numa linha semelhante, torna-se necessário compreender a nova propulsão que o princípio da preservação ao Meio Ambiente nos remete, de fato, é um princípio fundamental que necessita de proteção global. Talvez seja uma das formas positivas e tendenciais do processo de globalização a propagação dessa proteção de um bem da humanidade. Dando perspectiva ao bem protegido, nos direcionamos para uma possível tendência que deveria ser apreciada com maior

\footnotetext{
17 Sobre esse aspecto Paula ESCARAMEIA nos diz: 'Foi precisamente a percepção dessa situação que levou os negociadores a estabelecer uma distinção clara entre os conceitos de extradição e entrega no art. $102^{\circ}$, refletindo assim a diferença qualitativa entre relações horizontais Estado a estado e relações entre um Estado e o Tribunal. Esta distinção não é, evidentemente, meramente terminológica, mas traduz a realidade de dois modos de organização distintos, que atualmente se começam a interpretar, isto é, o modelo tradicional de cooperação judiciária entre Estados e o modelo emergente de cooperação com uma ordem judicial da comunidade mundial, que, por isso, assume a característica e reflete valores que se não podem subsumir a uma ordem estrangeira mas que antes espelham o consenso internacional". Cfr., ESCARAMEIA, Paula, op. cit, pp. 169.
} 
seriedade, trata-se do princípio da responsabilidade compartilhada que ao nosso ver ainda não vislumbrado nos aspectos mais críticos da proteção do princípio ambiental. Aliás, o aspecto de proteção global, em que condiz as questões ambientais passa a ser expresso nitidamente na Convenção da Biodiversidade que em 1968, a Assembléia Geral das Nações Unidas, conforme resolução 43/53, onde preocupa-se e reconhece as alterações climáticas e evidencia-se o quanto é uma preocupação global, ao passo de considerar como um interesse comum da humanidade. Nesse contexto, seria de extrema utilidade a consagração do princípio da solidariedade como propulsor e protetor. Em verdade, bem sabe-se que o mesmo não está referido expressamente, mas a doutrina já manifesta-se sobre seu papel preponderante e sua relevância e sua consciência jurídica universal ${ }^{18}$.

O que deve prevalecer e ser contributo para o futuro refere-se ao simples fato de que a natureza aberta que algumas constituições possuem, em especial do Brasil deve ser levado em consideração na hora de uma colisão, por uma simples razão altamente explícita a realidade ultrapassou em muito a estrutura em que assentavam os nossos pilares jurídicos e a prova cabal desse compreender demonstra-se dia a dia por meio dos princípios.

É notório que os objetivos e princípios da base constitucional no plano internacional — a Carta das Nações Unidas merece e deve atender as necessidades imposta através dos inúmeros desafios apresentados pela globalização, mas além disso é de extrema importância dar-se o valor real e dogmático jurídico que os princípios trazem do plano interno dos Estados, pois somente com essa sincronia poder-se-á aplicar ou exigir de um princípio a sua eficácia plena levando-se em conta as peculiaridades de cada Estado. Assim saberemos administrar, diante das complexidades internacionais que surgem no presente e que nos direcionam para a ideia de uma sociedade internacional consensual do século XXI, onde um dos desafios maiores referem-se pela busca de uma base estrutural adequada para um século em transição.

Ao referir sobre novos princípios, o texto nos direciona para a Declaração do Milênio e

\footnotetext{
${ }^{18}$ Cfr., NOVAIS, Reis Jorge. Os Princípios Constitucionais Estruturantes da República Portuguesa. Coimbra, $1 .^{\mathrm{a}}$ ed.
} (Reimp.), Lisboa, 2011, p. 291 e segs. 
um dos princípios debatidos refere-se, ao princípio da erradicação da pobreza. Observa-se, que tal princípio está elencado na Constituição do Brasil de 1988, menciona dentro do contexto dos direitos humanos, como dever do Estado a erradicação da pobreza e também menciona sobre a exclusão social. Acredita-se que tal princípio recebeu maior ênfase com a valorização dos direitos humanos, sendo uma proteção mundial.

O que merece destaque é a constatação de que o mínimo existencial está ligado à pobreza absoluta. Observa-se, nesse aspecto que deve ser totalmente combatida pelo Estado. A grande dificuldade é enquadrar o que seria esse mínimo existencial, mas nos inclinamos conforme o posicionamento de grande parte da doutrina ao sinalizar que seria um direito às condições mínimas de existência humana digna.

Na visão de Rawls, é perceptível que o mínimo existencial se diferencia do “princípio da diferença”, para ele o mínimo existencial refere-se a um elemento essencial, que independe de lei, o que diferencia do princípio da diferença que depende de lei. Para Rawls, o mínimo existencial é sim, um princípio constitucional, porém fora numa outra dimensão dos princípios básicos de justiça. ${ }^{19}$ Resta claro o quanto vivenciamos uma transição e no que diz respeito ao respectivo processo é notório as potenciais incompatibilidades entre princípios e modelos dos mais variados ordenamentos mundiais.

Sendo assim estamos em pleno processo de ajustes, onde alguns princípios fundamentais demonstram sua transformação em preferência de outra realidade que consubstanciase pelos mesmos princípios, porém numa dimensão interpretativa diferente, num momento diferente, num cenário global em constante mutação.

\footnotetext{
${ }^{19}$ RAWLS, John. Liberalismo político. Tradução de: Sergio René Madero Báez. México, 1996, p. 217 e segs.
} 


\section{Considerações Finais}

Enquadram-se nessas últimas considerações inúmeros pensamentos, talvez um pouco desordenados, mas o próprio processo de transição nos remete a essa sensação, pois estamos no exato intervalo dessa transição, onde uma boa dose de cosmopolitismo epistemológico e sem dúvida alguma uma considerável abertura de horizontes intelectuais foram de extrema necessidade para chegarmos a nova realidade internacional.

Com essa nova realidade, percebe-se a contradição entre abertura econômica e a tentativa de uma sociedade em busca de cooperação e reforma social baseada em alicerces como princípios fundamentais, onde a globalização nos impões enormes desafios, a começar pela própria tentativa de conceituar globalização. E logo após, ao nosso tema central que envolve princípios, aos impactos entre alguns princípios e suas necessidades em serem resolvidos diante de consenso por todos os Estados numa sociedade que caminha em moldes globais.

Compreende-se que a política da globalização rompe com alguns valores primordiais, mas da mesma forma, é notório o quanto nunca houve em tempos de modernidade tardia a necessidade de preservar-se tanto os direitos humanos, a erradicação da pobreza, o meio ambiente, a dignidade da pessoa humana e indubitavelmente nos deparamos com o vetor propulsor dos Estados em matéria de relações internacionais tão forte e cedente por mudanças como o princípio da independência nacional.

Bem compreende-se que compatibilizar alguns princípios não é tarefa fácil, mas de forma alguma deve-se rechaçar essa tentativa, pois estamos em busca de uma harmonia social que preza pelo resgate à cidadania, onde busca-se, incessantemente anular os conflitos, as incertezas e acredita nas boas perspectivas e analisa cada desafio da globalização através da regulação das relações internacionais como mecanismo de cooperação mundial, com lastros fortes no princípio da 
igualdade e responsabilidade compartilhada em épocas que são de todos e por todos. Assim, resume-se o presente texto, com uma simples passagem, mas de grande valia em tempos de profunda globalização. ${ }^{20}$

\section{REFERÊNCIAS BIBLIOGRÁFICAS}

CANOTILHO, José Joaquim Gomes. Direito Constitucional e Teoria da Constituição.

Coimbra, 7P ed., 11P reimp., 2003.

CRUZ, Ana Maria da Silva. Capítulo: Constitucionalismo. Desafios emergentes na era da globalização. HESPANHA, António Manuel; Tereza Pizarro Beleza (Coord.). Teoria da Argumentação e Neo-Constitucionalismo. Um conjunto de perspectivas. Coimbra, 2011.

DIAMOND, Jared. Armas, Germes e Aço. Rio de janeiro, 2005.

ESCARAMEI A, Paula. O Direito Internacional Público nos Princípios do Século XXI. Coimbra, 2003.

FIORATI, Jete Jane. Jus Cogens: as normas imperativas de Direito Internacional Público como modalidade extinta dos tratados internacionais. Franca, 2002.

FRIEDMANN, Wolfgang Gaston. Mudança da estrutura do Direito Internacional. Tradução de: A.S. Araujo, Rio de Janeiro, 1971.

\section{GARCÍA, Pedro de Vega. Mundialización y Derecho Constitucional: la crisis del Principio}

Democrático en el Constitucionalismo actual. Revista de Estudios Políticos. Madrid, n. ${ }^{\circ} 100$,

20 "Todos nós sabemos que a história avançou de modo muito diferente para os povos de cada parte do globo. Nos 13.000 anos que se passaram desde o fim da última Era Glacial, algumas partes do mundo desenvolveram sociedades industriais e letradas, que usavam utensílios de metal, enquanto outras produziram apenas sociedades agrícolas analfabetas e ainda outras se mantiveram caçadoras- coletoras de alimentos, usando artefatos feitos com pedras. Essas desigualdades projetaram grandes sombras sobre o mundo moderno, uma vez que as sociedades letradas que possuíam utensílios de metal conquistaram ou exterminaram as outras sociedades. Embora essas diferenças representem os fatos mais elementares da história mundial, suas causas continuam incertas e controvertidas. Essa intigrante questão me foi apresentada alguns anos atrás, de maneira simples e pessoal". Cfr. DIAMOND, Jared. Armas, Germes e Aço. Rio de janeiro, 2005, p. 13. 
1998.

HABERMAS, Junger. The European National States — Its Achievements and its Limits. On the Past and Future of Souvereignty and Citizenship. Challengs to Law at the End of the 20 th. Century. Bologna, v. VII, 1995.

MARTINS, Ana Maria Guerra. Estudos de Direito Público. Direito da União Européia Direito Internacional Público Direito Constitucional. Coimbra, v. I, 2003.

MARTINS, Ana Maria Guerra. Manual de Direito da União Europeia. Almedina, 2014.

MIRANDA, Jorge. A incorporação ao direto interno de instrumentos jurídicos de direito internacional humanitário e direito internacional dos direitos humanos. Revista CEJ. Brasília, n. ${ }^{\circ} 11,2000$

MIRANDA, Jorge. Manual de Direito Constitucional: Tomo I - Preliminares do Estado e os Sistemas Constitucionais. Coimbra, 7.a ed., 2003.

MIRANDA, Jorge. Teoria do Estado e da Constituição. Coimbra, 2002.

NOVAIS, Reis Jorge. Os Princípios Constitucionais Estruturantes da República Portuguesa. Coimbra, 1P ed. (Reimp.), Lisboa, 2011.

QUEIROZ, Cristina. Constituição, Constitucionalismo e Democracia. MIRANDA, Jorge (Org.). Perspectivas Constitucionais nos 20 anos da Constituição de 1976. Coimbra, 1996.

RAWLS, John. Liberalismo político. Tradução de: Sergio René Madero Báez. México, 1996.

RODAS, João Grandino. Jus Cogens em Direito Internacional. Revista da Faculdade de Direito de São Paulo. São Paulo, vol. 69, fasc. II, 1974.

SÁNCHES, Luis Pietro. Constitucionalismo y globalización. Dimensiones Jurídicas de la globalización. Madrid, 2007. 
SANTOS, Boaventura de Souza. A globalização e as ciências sociais. O processo da Globalização. São Paulo, 2002.

STRECK, Lênio Luiz. Hermenêutica Jurídica em Crise. Uma exploração hermenêutica da construção do Direito. Porto Alegre, 10P, 2011.

WANDERLEY JÚNIOR, Bruno; Dalvo Leal da Rocha. Processo de integração e globalização: um contraponto entre o discurso neoliberal e a construão de um espaço comunitário. Direito Internacional Contemporâneo. Leonardo Nemer Cladeira Brant, et. al. Curitiba, 2011.

http://www.un.org/ es/documents/charter/chapter12.shtml. 